\title{
Clinical assessment of depression and type 2 diabetes in Morocco: Economical and social components
}

\author{
Salma Bensbaa, Loubna Agerd, Saïd Boujraf ${ }^{1,2}$, Chadya Araab ${ }^{1,3}$, Rachid Aalouane ${ }^{1,3}$, Ismail Rammouz ${ }^{1,3}$, Farida Ajdi \\ Departments of Endocrinology, Diabetology and Nutrition, ${ }^{3}$ Department of Psychiatry, University Hospital of Fez, ${ }^{1}$ Clinical Neuroscience Laboratory, \\ ${ }^{2}$ Department of Biophysics and Clinical MRI Methods, University of Fez, Fez, Morocco
}

\begin{abstract}
Background: The global prevalence of diabetes is increasing worldwide. In Morocco, diabetes and depression are major public health problems, requiring improvement in their care. Diabetes and depression are associated with morbidity and early mortality. This association contributes to raising the risk of the complications that occur, while causing higher suffering to patients, as also an increased cost toward healthcare. Aim: This study aims to assess the prevalence of depression in patients with type 2 diabetes (T2D), and identify the main risk factors for depression in this category of diabetic patients. Patients and Methods: Type 2 diabetic patients and older than 18 years of age were recruited. The exclusion criteria included being type 1 diabetic, pregnant woman, hospitalized patients, a history of neurological disorders, such as, stroke, infectious episidodes, and history of psychiatric disorders. The individual patient data was collected through individual and confidential interviews lasting 30 minutes, at the end of the diabetology consultation, by the same diabetologist, trained to use the psychometric scales that were needed. The Moroccan-Arabic version of the Beck diagnostic scale of depression was used. Patients assessed with depressive disorders were reviewed in a specialized psychiatric consultation. The statistical analysis was achieved by using SPSS package (version 17). We retained a threshold $P$ value of 0.05 . Settings and Design: A cross-sectional study was conducted that included adults with type 2 diabetes. The depression diagnosis was performed using the Arabic version of the Beck Depression scale. Statistical Analysis: We included 142 patients with type 2 diabetes, with an average age of 56.26 years. The prevalence of depression was $33.1 \%$. The risk factors recognized for depression were, lack of social security, hypertension, and a history of type 2 diabetes of more than five years. Results and Conclusions: In this study, we have focused on the frequent association of 'Type 2 diabetes and depression' and the risk of mutual aggravation of both pathologies that might require multidisciplinary healthcare, as well as, improvement in the risk factors of depression through improved access to healthcare, with the extension of social security. The stability of the healthcare personnel involved in the treatment of both chronic diseases, including diabetes and hypertension screening, should also be considered for better management of psychiatric complications.
\end{abstract}

Keywords: Degenerative complications, depression, risk factors, type 2 diabetes

\section{Introduction}

World prevalence of diabetes is constantly increasing. In fact, more than 285 million patients are suffering from diabetes in the world and will increase to 438 millions in the year 2030 , with $70 \%$ of the patients

\begin{tabular}{|l|l|}
\hline \multicolumn{2}{|c|}{ Access this article online } \\
\hline Quick Response Code: & Website: \\
\hline & www.ruralneuropractice.com \\
\cline { 2 - 2 } & \\
\hline & \\
\hline
\end{tabular}

belonging to developing countries. ${ }^{[1]}$ In Morocco, diabetes and depression constitute a major public health problem. ${ }^{[2,3]}$

According to the National Investigation of Risk Factors of Cardiovascular Diseases achieved in 2000, the prevalence of diabetes has increased from $2.26 \%$ in 1976 to $6.6 \%$ in 2000 . Diabetes represents $8.7 \%$ in people older than 30 years of age, and $11.5 \%$ in people over 40 years of age. Indeed, type 2 diabetes (T2D) is found to constitute $90 \%$ of all cases of diabetes. ${ }^{[2]}$

In Morocco, one of four people suffers from a major depressive episode during their life. Besides this, the incidence increases among women in urban areas. ${ }^{[3]}$

\section{Address for correspondence:}

Prof. Saïd Boujraf, Clinical Neurosciences Laboratory, Department of Biophysics and Clinical MRI Methods; Faculty of Medicine and Pharmacy, University of Fez, BP. 1893; Km 2.200, Sidi Hrazem Road, Fez 30000, Morocco. E-mail: sboujraf@gmail.com 
Epidemiological studies showed that T2D and depression were not spontaneously associated, but could complicate health issues mutually, in the context of missing therapeutical care.

Indeed, the observance of life hygiene and dietary rules constitute the basis for treating T2D, particularly in the case of depression, hence, the complication risks of T2D increase with mood disorder. In addition, depression might prove to be a risk factor for T2D. ${ }^{[4]}$

We conducted a study on patients suffering from T2D, who were followed in the University Hospital of Fez, Morocco. This study aimed to assess the depression prevalence in T2D patients. The correlation between the T2D parameters and depression was assessed, to suggest better care and a better control of diabetes and its complications. This would allow a better quality of life for T2D patients.

\section{Patients and Methods}

This transverse study recruited external patients from the Diabetology Department of the University Hospital of Fez, Morocco.

The inclusion criteria consisted of being a Type 2 diabetic and older than 18 years of age. Informed consent from the patients was also obtained. The exclusion criteria included being type 1 diabetic, pregnant woman, hospitalized patients, a history of neurological disorders, such as, stroke, and history of psychiatric disorders, including consequences of recent death and separation. Patients with infectious episodes that might cause an imbalance in their diabetes were also excluded.

The collection of individual patient data was done through individual and confidential interviews lasting 30 minutes, at the end of the diabetology consultation, by the same diabetologist, trained to use the psychometric scales that were needed. The Moroccan-Arabic version of the Beck diagnostic scale of depression was used ${ }^{[5]}$ Patients assessed with depressive disorders were reviewed in a specialized psychiatric consultation.

The statistical analysis was achieved by using SPSS package (version 17). We retained a threshold $P$ value of 0.05 .

\section{Results}

One hundred and forty-two T2D patients were considered; their average age was $56.26 \pm 9$ years $-65.5 \%$ were women.
The depression prevalence in our diabetic population was $33.1 \%$, with an average age of $56.68 \pm 8.42$ years, without any gender difference. The depression was found to be higher in unmarried patients compared to married patients, without any significant statistical difference.

A low educational level was strongly correlated with depression of T2D patients, with a threshold $P$ value of 0.01 [Figure 1]. The living environment of life (urban versus rural) and low economic income were not found to significantly impact depression in our T2D patients. About $43.3 \%$ of our patients were without social security, and this factor was indeed strongly associated with depression in our T2D patients, with a $P$ value of 0.001 [Figure 2].

Type 2 diabetes evolving for more than five years was strongly associated with depression, with a $P$ value of 0.01 .

The average age at which T2D evolved in depressed patients was $8.85 \pm 6.34$ years compared to $6.41 \pm 6.46$ years in T2D patients without depression [Figure 3].

The average $\mathrm{HbA} 1 \mathrm{c}$ of all patients was $7.86 \pm 2.01 \%$. In fact $40.1 \%$ of the patients did show degenerative complications of diabetes with a possibility of multiple simultaneous complications. Imbalanced glycemia and degenerative complications or microangiopathies were not demonstrated to be risk factors of depression.

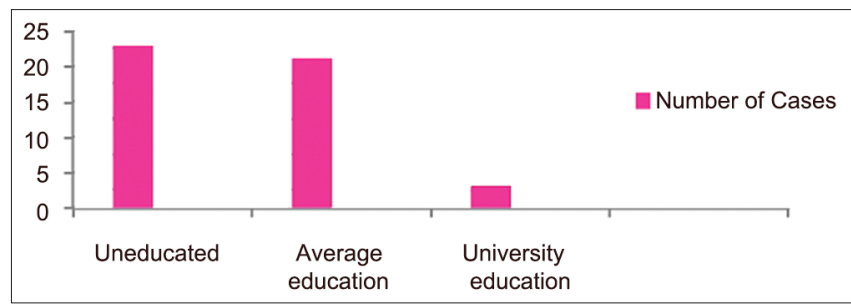

Figure 1: Depression prevalence according to the education level

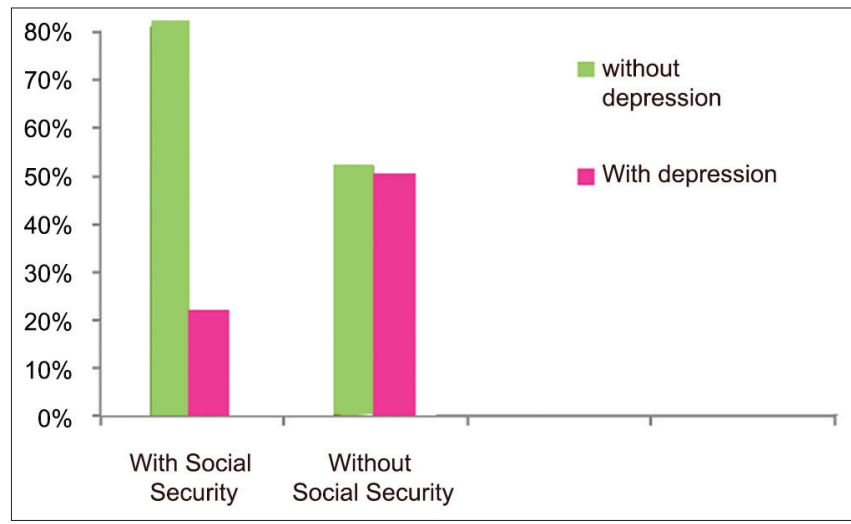

Figure 2: Depression rates and social security 
The T2D therapy for patients consisted of oral antidiabetic agents in $48.6 \%$, antidiabetic agents associated with insulin at bedtime in $26.1 \%$, exclusive insulin therapy in $17.6 \%$, and exclusive diet in $7.7 \%$. Besides, $64.1 \%$ of our patients had regular physical activity.

There was neither a significant link between the medication type, nor the adherence to hygiene/dietary rules and depression in T2D.

In contrast, we found a very significant association between depression and coexistence of high blood pressure (HBP) in T2D, with a $P$ value of 0.009 [Figure 3].

The multivariate analysis, using logistic regression for establishing independent risk factors of depression in T2D patients, found the factors to be, missing social security, HBP, and the length of history of T2D of more than years.

\section{Discussion}

Diabetes is a chronic disease that is associated with high morbidity and mortality. ${ }^{[6]}$ This pathology is constantly increasing worldwide, as diabetes constitutes stress with emotional reaction and should be accompanied by acceptance and psychological adaptation. Therefore, diabetes is a major risk factor for depression. ${ }^{[7]}$ Besides, the data showed that depression could also be a risk factor for physical diseases. ${ }^{[8]}$

The prevalence of depression in T2D is considerably higher compared to the general population and varies between 12 and $44 \%$. The incidence of depression is low in T2D patients of western countries, whereas, it is higher in patients in developing countries. ${ }^{[9-12]}$

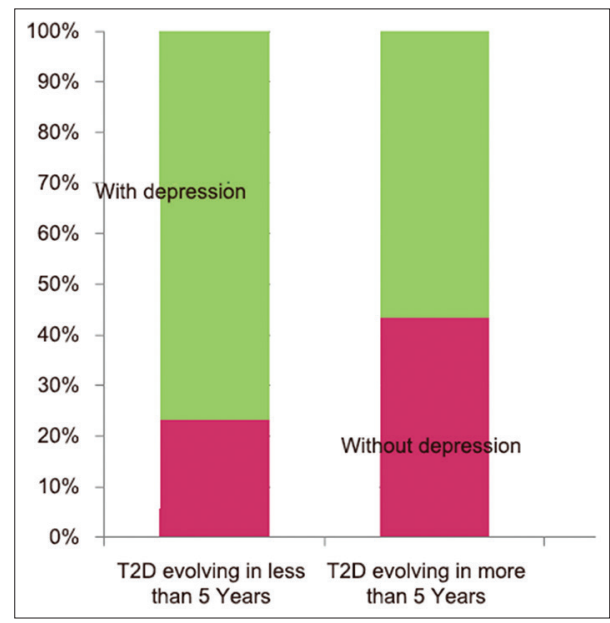

Figure 3: Rate of depression and T2D history duration
The predominance in women has been proved, and probably originated from a cultural perception. ${ }^{[11-14]}$ Indeed, our study confirmed the reported results that the prevalence of depression is higher in T2D unmarried patients compared to married patients. ${ }^{[1]}$

The educational level and missing social security were associated with higher depression rates in T2D patients [Figure 4]. Our findings were similar to the reported literature. ${ }^{[10-16]}$

Indeed in developing countries, missing social security, a lower educational level, a higher poverty level, and acute financial difficulties were the sources of stress responsible for the feelings of insecurity, leading to T2D, and making it a chronic disease.

Our study showed that a T2D patient history of longer than five years was also associated with an occurrence of depression; our results also conformed to those in the earlier published literature. ${ }^{[11,17,18]}$

In fact, an increased duration of T2D contributes significantly to an increase in the risk of diabetic complications. Therefore, these patients are more susceptible to experiencing psychiatric diseases.

Glycemia-imbalance associated depression occurrence in T2D patients has been reported in literature. ${ }^{[9,12,13]}$ This association was not revealed in our patients; obviously this was related to anorexia originated by depression. This explains the higher rate of physical activity in T2D-depressed patients reported in literature; ${ }^{[9,14]}$ however, this association was not revealed in our patients.

Most studies reported a very strong relationship between the presence of depression and degenerative complications of $\mathrm{T} 2 \mathrm{D},{ }^{[9,19]}$ which was not found in our study. This was probably due to the under-diagnosed degenerative complications in our patients due to the missing social security and low economic income of

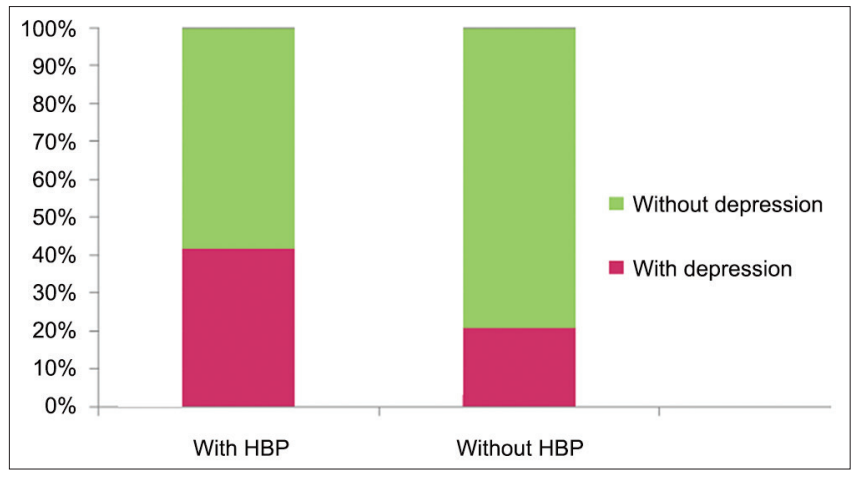

Figure 4: Prevalence of depression and educational level 
Table 1: Risk factor of depression in T2D patients

\begin{tabular}{lccc}
\hline Risk factor type & OR & Cl 95\% & $\boldsymbol{P}$ \\
\hline Social security & 0.264 & $0.10-0.71$ & 0.008 \\
HBP & 2.89 & $1.24-6.77$ & 0.01 \\
Diabetes $>$ 5 years & 2.72 & $1.18-6.26$ & 0.02 \\
\hline
\end{tabular}

$\mathrm{HBP}$ - High blood pressure, OR - Odds ratio, $\mathrm{Cl}$ - Confidence Interval

the patients, which did not allow the achievement of complementary explorations that are expensive, as also the evaluation duration of T2D, which is too short.

Cardiovascular diseases are demonstrated to be an independent risk factor of depression in studies on T2D patients. ${ }^{[20,21]}$

A positive contribution by $\mathrm{HBP}$ has been noticed to be a cause of an increase in depression rates in T2D patients. ${ }^{[22]}$ Indeed our study has demonstrated a high correlation between depression and HBP in T2D patients [Table 1]. HBP is a chronic disease associated with severe complications requiring intense treatment, which is sometimes unaffordable by a great number of our patients. This constitutes an additional stress factor contributing to depression in T2D patients.

\section{Conclusion}

Type 2 diabetes patients show a higher predisposition to depression. T2D and depression are associated with higher morbidity and early mortality. The association of these factors increases the suffering and healthcare cost of patients.

The association of T2D and depression might mutually worsen and constitute a public health problem requiring multidisciplinary medical involvement including psychiatric care, by making social security available.

Hence, we suggest that T2D patients obtain the available network of medical care, including a diabetologist, psychiatrist, and psychologist, with medical staff who are aware about the psychological issues, while being involved in the treatment of chronic diseases such as diabetes and HBP.

\section{References}

1. Diabetes Atlas, The International Diabetes Federation (IDF) http:// www.idf.org/diabetes-atlas-2012-update-out-now.

2. Tazi MA, Abir-Khalil S, Chaouki N, Cherqaoui S, Lahmouz F, Sraïri JE, et al. Prevalence of the main cardiovascular risk factors in Morocco: Results of a National Survey, 2000. J Hypertens. 2003;21:897-903.

3. Asouab F, Agoub A, Kadri N, Battass O, Moussaoui A et al. Prévalences des troubles mentaux dans la population générale marocaine (enquête nationale 2005). Bulletin Epidémiologique ministère de la santé royaume du Maroc; Décembre 2007. Pp. 61-4.

4. Boureau F, Fouberere JF, Luu M. Conduite à tenir face à une douleure chronique. Ency Med Chir (Paris-France). Thérapeutique, 25-14-B10. 1993. p. 9.

5. Cottraux J. Clinical and psychometric evaluation of depressive states. Collection scientifique survector, Edition: Neuilly-sur-Seine (41, rue Ybry, 92201 France): Éuthérapie, 1986.

6. Gupta R, Misra A. Type 2 diabetes en India: Les disparitésrégionales. Br J Vasc Dis Diab 2007;7:12-6.

7. Wilhelm K, Mitchell P, Slade T, Brownhill S, Andrews G. Prevalence and correlates of DSM-IV major depression in an Australian national survey. J Affect Disord 2003;75:155-62.

8. Wulsin LR, Vaillant GE, Wells VE. A systematic review of the mortality of depression. Psychosom Med. 1999 Jan-Feb; 61:6-17.

9. Rkik N, Kammoun M, Minif L, Dammak R, Charfi N, Jaoua A, et al. Les troubles anxio-depressifs au cours du diabète. Diabetes and Metabolism-Vol 36-Supplément 1-mars 2010: A71.

10. Camara A, Sobngwi E, Moussa Baldé N, Baldé S, Oumar BT, Malal Bah M, et al. Anxiété et dépression: Fréquences et facteurs associés chez 435 diabétiques suivis en Guinée. Diabetes and Metabolism-Vol 37-Numéro 1 Supplément 1-mars 2011; A36-108.

11. Khuwaja AK, Lalani S, Dhanani R, Azam IS, Rafique G, White F. Anxiety and depression among outpatients with type 2 diabetes: A multi-centre study of prevalence and associated factors. Diabetol Metab Syndr 2010;2:72.

12. Papelbaum M, Moreira RO, Coutinho W, Kupfer R, Zagury L, Freitas S, et al. Depression, glycemic control and type 2 diabetes. Diabetol Metab Syndr 2011;3:26.

13. Zuberi SI, Syed EU, Bhatti JA. Association of depression with treatment outcomes in Type 2 Diabetes Mellitus: A cross-sectional study from Karachi, Pakistan. BMC Psychiatry 2011;11:27.

14. Balhara YP, Sagar R. Correlates of anxiety and depression among patients with type 2 diabetes mellitus. Indian J Endocrinol Metab 2011; 15(Suppl 1):S50-4.

15. Mirza I, Jenkins R. Risk factors, prevalence, and treatment of anxiety and depressive disorders in Pakistan: Systematic review. BMJ 2004;328:794.

16. Khuwaja AK, Kadir MM. Gender differences and clustering pattern of behavioural risk factors for chronic non-communicable diseases: Community-based study from a developing country. Chronic Illn 2010; 6:163-70.

17. Almawi W, Tamim H, Al-Sayed N, Arekat MR, Al-Khateeb GM, Baqer A. et al. Association of comorbid depression, anxiety, and stress disorders with Type 2 diabetes in Bahrain, a country with a very high prevalence of Type 2 diabetes. J Endocrinol Invest. 2008;31:1020-4.

18. Iype T, Shaji SK, Balakrishnan A, Charles D, Varghese AA, Antony TP Cognition in type 2 diabetes: Association with vascular risk factors, complications of diabetes and depression. Ann Indian Acad Neurol 2009;12:25-7.

19. Masmoudi J, Damak R, Zouari H, Ouali U, Mechri A, et al. Prevalence and Impact of Anxiety and Depression on Type 2 Diabetes in Tunisian Patients over Sixty Years Old. Depress Res Treat 2013 (2013), Article ID 341782, 6 pages.

20. Lin EH, Rutter CM, Katon W, Heckbert SR, Ciechanowski P, Oliver MM et al. Depression and advanced complications of diabetes: A prospective cohort study. Diabetes Care 2010;33:264-9.

21. Katon W, Russo J, Lin EH, Heckbert SR, Ciechanowski P, Ludman EJ, et al. Depression and diabetes: Factors associated with major depression at five-year follow-up. Psychosomatics 2009;50:570-9.

22. Thomas J, Jones G, Scarinci I, Brantley P. A descriptive and comparative study of the prevalence of depressive and anxiety disorders in low-income adults with type 2 diabetes and other chronic illnesses. Diabetes Care. 2003;26:2311-7.

How to cite this article: Bensbaa S, Agerd L, Boujraf S, Araab C, Aalouane R, Rammouz I, et al. Clinical assessment of depression and type 2 diabetes in Morocco: Economical and social components. J Neurosci Rural Pract 2014;5:250-3.

Source of Support: Nil. Conflict of Interest: None declared. 